\title{
How Institutions Evolve: Evolutionary Theory and Institutional Change
}

\author{
Orion A. Lewis \\ Rohatyn Center for International Affairs \\ Middlebury College \\ Sven Steinmo \\ European University Institute \\ Last Submitted: May 11, 2012
}

Key Words:

institutional change, evolutionary theory, new institutionalism, generalized Darwinism, cognitive science

\begin{abstract}
:
This article argues that questions of gradual institutional change can be understood as an evolutionary process that can be explained through the careful application of "generalized Darwinism." We argue that human's advanced cognitive capacities contribute to an evolutionary understanding of institutional change. In constantly generating new variation upon which mechanisms of selection and replication operate, cognition, cognitive schemas, and ideas become central for understanding the building of human institutions, as well as the scope and pace of their evolution. Evolutionary theories thus provide a broad theoretical framework that integrates the study of cognition, ideas and decision making with other literatures that focus on institutional change and human evolution.
\end{abstract}

Authors are listed in order of contribution. The authors would like to specifically thank Ian S. Lustick, Henry Farrell, Mark Blyth, James A. Morrison, and Jessica Teets for their feedback on earlier drafts, as well as all of the participants in the "Author Meet's His Critic's" roundtable held for Sven Steinmo at APSA in Seattle in 2011. This paper is also the product of the insightful contributions of numerous participants in the workshop "Do Institutions Evolve?" held in May 2009 at the Schumann Center at the European University Institute, and the helpful contributions of three anonymous reviewers. 
In recent years, political scientists have devoted considerable attention to the problem of explaining institutional change. Institutions change all the time, but as many have argued, the theoretical and epistemological tools used by political scientists are better equipped for the study of equilibrium and stasis. ${ }^{1}$ Put simply, change has been a vexing problem for rationalists because they tend to assume relatively static preferences, as well as for historicists because they tend to see institutions as consistent and stable constraints on behavior.

This article argues that gradual institutional change can be understood as an evolutionary process. We do not use evolution as a metaphor. Instead, we contend that human social institutions literally "evolve" and that this process can be understood as one example of "generalized Darwinism." ${ }^{2}$ We do not mean to suggest that biological evolution and institutional evolution are identical processes. Instead, we build on the growing body of literature that argues that biology is just one arena in which evolutionary processes take place.

We also argue that an evolutionary approach to social institutions dovetails remarkably well with similar trends in the literature on institutional change both within political science and in cognate fields of study, including economics, sociology, anthropology, and psychology. We show the link between institutionalist scholars in political science and the work of the growing

\footnotetext{
${ }^{1}$ Margaret Levi, "A Model, a Method and a Map: Rational Choice in Comparative and Historical Analysis," in Comparative Politics, ed. Mark I. Lichbach and Alan S. Zuckerman (New York: Cambridge University Press, 1997); Robert C. Lieberman, "Ideas, Institutions, and Political Order: Explaining Political Change," The American Political Science Review 96, (2002); James Mahoney and Kathleen Ann Thelen, "Explaining Institutional Change: Ambiguity, Agency, and Power," (New York: Cambridge University Press, 2010); Wolfgang Streeck and Kathleen A. Thelen, "Introduction: Institutional Change in Advanced Political Economies," in Beyond Continuity, ed. Wolfgang Streeck and Kathleen Thelen (Oxford: Oxford University Press, 2005).

${ }^{2}$ HE Aldrich et al., "In Defence of Generalized Darwinism," Journal of Evolutionary Economics 18, (2008).
} 
number of scholars in other fields who have argued that "universal Darwinism" can explain human institutional development. ${ }^{3}$

To be clear, we are not suggesting that political scientists can or should blindly import explanations from evolutionary biology. Humans have the most advanced capacities for abstract thought and communication, as well as mechanisms for information storage and replication of any species. But instead of arguing that humans' special cognitive characteristics abrogate or nullify evolutionary mechanisms in social institutions, we argue that humans' advanced cognitive capacities - and the use of ideas, framing and communication — shape the particular nature of institutional evolution. These characteristics of human social systems mean that evolutionary inheritance can operate both vertically, via genetic replication, as well as horizontally, via the "acquired" inheritance of political institutions and other non-genetic inheritance systems. ${ }^{4}$ Building on this line of thought, this article suggests that a model of

\footnotetext{
${ }^{3}$ GM Hodgson and T Knudsen, "Why We Need a Generalized Darwinism, and Why Generalized Darwinism Is Not Enough," Journal of Economic Behavior \& Organization 61, (2006); Eva Jablonka and Marion J. Lamb, Evolution in Four Dimensions : Genetic, Epigenetic, Behavioral, and Symbolic Variation in the History of Life, Life and Mind (Cambridge, Mass.: MIT Press, 2005); Richard Nelson, "Universal Darwinism and Evolutionary Social Science," Biology and Philosophy 22, (2007); KR Popper, "Natural Selection and the Emergence of Mind," Evolutionary epistemology, rationality, and the sociology of knowledge, (1987); Peter J. Richerson and Robert Boyd, Not by Genes Alone : How Culture Transformed Human Evolution (Chicago: University of Chicago Press, 2005). Indeed, the cover article of the October 14, 2010 issue of prestigious science journal, Nature, argues that political development is best explained as an evolutionary process. See T. Currie, et. al., "Rise and Fall of Political Complexity in Island South-East Asia and Pacific," Nature, Oct. 14, 2010, pp.801-804.

${ }^{4}$ In their work on different types of heredity systems Jablonka and Lamb argue that symbolic heredity systems do not exist "instead of the DNA transmission system; they are additional to it." They point out "these additional systems allow variations in a different type of information to be transmitted. These variations occur at a higher level
} 
institutional evolution offers the possibility of bringing human cognition and "ideas" back into our understanding of change.

of organization - at the cell, organism or group level. They may be quite independent of variations at the genetic level." Evolution in Four Dimensions, p. 110. 


\section{Evolution as a General Theory}

Richard Dawkins is credited with coining the phrase "universal Darwinism," which refers to the notion that evolutionary processes can be reduced to a very simple algorithm: variation, selection, retention. ${ }^{5}$ In this view, the evolutionary change does not just apply to biological phenomenon. It is, instead, a universal phenomenon that characterizes a wide variety of complex systems. "Modern evolutionary theorists," Eric Beinhocker summarizes, "believe that, like gravity, evolution is a universal phenomenon meaning that no matter whether the algorithm is running in the substrate of biological DNA, a computer program, the economy, or the substrate of an alien biology on a distant planet, evolution will follow certain general laws in its behavior." ${ }^{6}$ Charles Darwin, and later Karl Popper, believed that evolutionary theory might be applied beyond biology to explain the evolution of human language, knowledge, and culture. ${ }^{7}$

Philosopher Daniel Dennett, building on Dawkins' notion of a universal Darwinism, argues that natural selection can be seen as a simple algorithm to explain evolutionary change writ large. ${ }^{8}$ Noting Darwin's insight that the core evolutionary mechanism is variation, Dennett suggests that evolution can occur in any substrate where there are mechanisms generating

\footnotetext{
${ }^{5}$ Richard Dawkins, "Universal Darwinism," in Evolution from Molecules to Men, ed. D. S. Bendall (Cambridge: Cambridge University Press, 1983).

${ }^{6}$ Eric D. Beinhocker, The Origin of Wealth : Evolution, Complexity, and the Radical Remaking of Economics (Boston, Mass.: Harvard Business School Press, 2006).

${ }^{7}$ Aldrich et al., "In Defence of Generalized Darwinism."; Charles Darwin, The Descent of Man, 2nd [1904] ed. (New York: American Home Library, 1874); Popper, "Natural Selection and the Emergence of Mind."; Nelson, "Universal Darwinism and Evolutionary Social Science."

${ }^{8}$ Daniel C. Dennett, Darwin's Dangerous Idea (New York: Simon and Schuster, 1995). For a cautionary note in this regard, see Gary Cziko, Without Miracles : Universal Selection Theory and the Second Darwinian Revolution (Cambridge, Mass.: MIT Press, 1995); Nelson, "Universal Darwinism and Evolutionary Social Science."
} 
continued variation. In biology this mechanism is random genetic variation. Dennett suggests, however, that this need not be the only generator.

We argue that humans' creative capacities and problem-solving abilities are important mechanisms for generating continued variation in human social systems. Humans' creative capacities and their advanced ability to generate novel ways of solving collective action problems are perhaps the most distinctive features of our species. While all social creatures have elaborate social rules that govern behavior (in other words, institutions), humans' remarkable facility for questioning, breaking down, changing, or creating new rules distinguishes the human species. Human creative cognitive capacities therefore can help explain the complexity of political institutions, the opportunities for new variation to emerge, and the likely rates of institutional change.

Anthropologists Peter Richerson and Robert Boyd have also argued that humans' advanced cognitive capacities and decision making are key institutional selection mechanisms. ${ }^{9}$ In the biological world, mutations are repeatedly tested within the environment. The environment selects those mutations that are relatively fit. We submit that human's advanced capacities for learning are a key selection mechanism for institutional evolution. Clearly, processes of constant iterated trial-and-error learning are manifested extensively throughout human social systems. Karl Popper also argued along these lines, observing that "trial and error" methods are central to the evolution of knowledge. Similarly, Eric Beinhocker has used the concept of "deductive tinkering" to explain economic innovation and development. ${ }^{10}$ In these

\footnotetext{
${ }^{9}$ Robert Boyd and Peter J. Richerson, Culture and the Evolutionary Process (Chicago: University of Chicago Press, 1985); Richerson and Boyd, Not by Genes Alone : How Culture Transformed Human Evolution.

${ }^{10}$ Beinhocker, The Origin of Wealth : Evolution, Complexity, and the Radical Remaking of Economics; Popper, "Natural Selection and the Emergence of Mind."
} 
cases, humans' capacities for deductive problem solving and inductive learning complement each other and contribute to the selection of laws and new political institutional rules and schemas.

Finally, for there to be evolutionary change, the system must have mechanisms for retaining selected variations. We elaborate below how the mind's cognitive schemas develop within institutional and social systems and thus become part of the intergenerational transmission of collective norms and behavior. Routines, schemas and cognitive frames are at once in the individual actor's mind and part of the social structures and processes in which they are constructed. As such they become key mechanisms facilitating the intergenerational transfer of both beliefs and norms. Humans are reasoning creatures, but only rarely do we recalculate and 'rationally' assess all choices possible when making a decision. Since we form these mental schemas in a densely institutionalized ecology, the interaction between institutions and the mind becomes the mechanism for the retention collective social behavior over time.

This ensures that innovations are replicated and proliferate within the system. Understanding the means of institutional replication allows one to explain the proliferation of political paradigms across time, as well the scope of continued variation of alternative ideas within the system.

The final sections of this article make the case that humans' creative intellectual and communicative capacities define the speed and scope of institutional evolution. The cognitive basis of institutions-built on well-ingrained cognitive schemas-makes them particularly malleable and susceptible to emergence of new ideas. At their most basic cognitive level, institutions are sets of mental rules and schemas that drive our desires to reduce and replicate specific behaviors in specific contexts. Ideas perform the same function as mutations in 
biological systems - imperfectly replicating institutional structures in a way that generates new variation and hybrid forms of change over time. It is precisely the abilities of social animals, such as humans, to copy behavioral schemas and social rules that make complex social organization possible and endogenous institutional change more rapid than is often assumed.

\section{What Evolution Is and Is Not}

Understanding evolutionary institutional change as a product of a theoretical algorithm of generalized Darwinism distinguishes this model from other theories of change that look at an array of specific mechanisms and proximate causes for local phenomena. In this framework, institutional change adheres to the basic algorithm noted above. Simple one-off deviations in an agent's behavior, or their single efforts to shape behavior with new rules and laws, will not cause "institutional evolution" unless that policy idea is both "selected" by decision-makers and "replicated" across other individuals, organizations, and institutions. A schema must survive and eventually replicate if it is to have a truly "evolutionary" impact on institutions.

Evolutionary theory is an "interactionist paradigm." "What this means is that the theory does not a priori privilege either structural (that is, selection) or agency-centered (that is, variation) explanations. Both are key component parts of the overall evolutionary process. ${ }^{12} \mathrm{We}$ emphasize cognitive/agency based arguments in this essay, but we do not wish to imply that broader environmental mechanisms are not also at work. Our argument is not thus different from, Nadav Shelef's, who divides explanations for the evolution of Israeli nationalism between top-

\footnotetext{
${ }^{11}$ Kenrick, D., J. Maner, et al. (2002). "Dynamical Evolutionary Psychology: Mapping the Domains of the New Interactionist Paradigm." Personality and Social Psychology Review 6(4): 347-356.

${ }^{12}$ Ernst Mayr, What Evolution Is (New York: Basic Books, 2001).
} 
down "elite imposition" factors and bottom-up "rational adaptation" on the part of agents. ${ }^{13}$ In Shelef's framework only the latter is considered "evolutionary," while the former is deemed "rational." In our framework, "elite imposition" structural factors are selection mechanisms that winnow certain ideas relative to others. "Rational adaptation" from below represents one variant among many possible adaptive responses to relative structural pressures. The collective decisions of agents at the grassroots level also constitute a selection mechanism operating at lower levels of analysis. In sum, an evolutionary framework does not privilege the direction of causality. Selection and variation are essentially different components of an overall endogenous "evolutionary" account of institutional change. While certain mechanisms of change may be relatively more important at different points in time, generalized Darwinism focuses solely on the process of change as a basic ontological condition.

Given the widespread misconceptions and political misappropriations of evolutionary theory in the past, it is very important to understand that evolutionary outcomes are not necessarily efficient, linear, or optimizing. Darwin did not invent term "survival of the fittest," and evolution by natural selection was not conceived of as an aggregated optimization algorithm. Nor are these misconceptions embraced by evolutionary theorists today. ${ }^{14}$ By natural selection, Darwin meant that some behavioral or physical traits might give competitive advantage to individuals or populations within their local environment. Random variation would not create evolutionary changes unless some of those variations moderately benefited the carriers of the

\footnotetext{
${ }^{13}$ Nadav G. Shelef, Evolving Nationalism : Homeland, Identity, and Religion in Israel, 1925-2005 (Ithaca: Cornell University Press, 2010).

${ }^{14}$ It was sociologist Herbert Spencer who coined this phrase. Thomas H. Huxley was largely responsible for promoting a view of Darwinism as unending struggle and conflict. John R. Alford and John R. Hibbing, "The Origins of Politics: An Evolutionary Theory of Political Behavior," Perspectives on Politics 2, (2004)..
} 
trait. But this in no way implies that these macro outcomes are in some teleological way superior to other outcomes. Moreover, as many evolutionary theorists have pointed out, most evolutionary outcomes are dead ends. Just because a variation (or an idea) can prosper or survive in one local ecology, does not necessarily imply that it will thrive in another.

Many evolutionary theorists have highlighted selection is "myopic," allowing multiple traits to survive and proliferate locally. Evolutionary theorists Hodgson and Knudsen point out this is why selection is not necessarily moral, just, or "optimizing." 15 Selection only means that a trait is advantageous within a particular environment, which promotes the survival of that trait. However, numerous traits can survive simultaneously without being the optimal solution to an environmental challenge. The notion that evolution implies a clear, consistent, and progressive optimizing pattern—or a linear change toward greater complexity—is fundamentally wrong. ${ }^{16}$ Moreover, numerous social scientists have documented how a myopically generated selection or advantage in one part of the system often creates problems for other bureaucracies - giving rise to "institutional friction" within a political system. ${ }^{17}$ As we will outline below, the inherent frictions in complex social institutions are re-enforced by the imperfections in how institutions are replicated.

\footnotetext{
${ }^{15}$ Hodgson and Knudsen, "Why We Need a Generalized Darwinism."

16 The widespread misconception that evolution implies a progressive optimizing pattern has been appropriated for benign programs, such as the progressive movement in the United States, as well as heinous acts, such as Nazi eugenics. Highlighting these misconceptions and promoting an accurate understanding of evolutionary theory remain important challenges for evolutionary social science.

${ }^{17}$ Lieberman, "Ideas, Institutions, and Political Order: Explaining Political Change."; U Pagano, "Legal Positions and Institutional Complementarities," Revista de Economİa Institucional 5, (2003).
} 
Finally, it should be understood that evolutionary systems are rarely at equilibrium. Though one may find long periods of relatively slow change - what is more correctly called stasis - true equilibrium is impossible both because the environment in which systems evolve changes and because an evolutionary system itself generates continued variation. This approach is thus different from an approach that assumes systems reach equilibrium and are occasionally disturbed or punctuated.

\section{Choice and Evolution}

Some critics of generalized Darwinism have argued that humans are uniquely intentional in their behavior, making "biological analogies" inappropriate explanations. According to the critics, one of the most remarkable features of humankind is our highly developed cognitive capacity. We are self-conscious, capable of building and sustaining highly complex social organizations, and able to quickly learn and copy behaviors from others to a greater extent than any other species. Richard Nelson, for example, argues that these attributes raise important questions about the mechanisms of human institutional evolution, because strategic choice means that the process of change does not occur only through "blind" genetic replication. ${ }^{18}$

Human agents intentionally design social institutions. One of the most interesting challenges when applying evolutionary theory to human social institutions involves the incorporation of human cognition and agency into the theory precisely because in biological evolution outcomes are non-purposive. ${ }^{19}$ Once again, specific evolutionary changes are the

\footnotetext{
${ }^{18}$ Nelson, "Universal Darwinism and Evolutionary Social Science."

${ }^{19}$ There have been many interesting analyses of randomness in evolutionary theory. See, for example, John Alford and John Hibbing, "The Origins of Politics: An Evolutionary Theory of Political Behavior," Perspectives on Politics 2, (2004); Robert M. Axelrod, An Evolutionary Approach to Norms (1986); Leda Cosmides and John
} 
products of myopically generated trial-and-error tests within a specific ecological context. While one can argue that the "purpose" of the system at its most general level is to increase the chances that the individual will be able to pass on its genes, one cannot say that specific behavioral or genetic changes are the products of conscious "decisions" inside the system. Human social institutions evolve differently precisely because human cognitive capacities make it possible for individuals and groups to consciously choose institutions.

These considerations have led some evolutionary scientists to revisit Lamarckian theories of evolution that point to the inheritance of "acquired" traits. According to Jean-Baptiste Lamarck, individuals acquired traits over the course of their lifetime from the use or disuse of certain functions and were able to pass these traits to later generations. In other words individuals were able to pro-actively adapt to environmental challenges rather than simply be the passive recipients of selection pressures. As evolutionary theory has developed, Lamarckianism has become juxtaposed against Darwinism and has been labeled the "incorrect" form of

Tooby, "Evolutionary Psychology: A Primer," University of California, Santa Barbara; Edward Countryman, The American Revolution (New York: Hill and Wang, 1985); Ernst Fehr and Urs Fischbacher, "Third-Party Punishment and Social Norms," Evolution and social behavior 25, (2004); Richard Lewontin, The Triple Helix: Gene, Organism and Environment (Cambridge: Harvard University Press, 2000); Talcott Parsons, "Evolutionary Universals in Society," American Sociological Review 29, (1964); Gerard Radnitzky, William Warren Bartley, and Karl R. Popper, Evolutionary Epistemology, Rationality, and the Sociology of Knowledge (La Salle Ill.: Open Court, 1987); Gordon Wood, The Radicalism of the American Revolution (New York: Vintage Books, 1991); Dennett, Darwin's Dangerous Idea; Cziko, Without Miracles : Universal Selection Theory and the Second Darwinian Revolution.. 
evolution. However, Jablonka and Lamb point out that this debate presents a false dichotomy. ${ }^{20}$ They argue, accepting that the environment has a role in inducing variation in no way weakens Darwin's theory of evolution by natural selection. On the contrary, if new variation can arise in response to the conditions of life, it increases the amount of variation and the scope for natural selection. $^{21}$

Their framework bolsters the case for applying generalized Darwinism to explain human institutions because communication and the proliferation of ideas provide an additional "nongenetic" inheritance system that fosters additional mechanisms for evolutionary change. Richerson and Boyd add:

Given that decision rules derive from the action of selection on genes and hence are adaptive, on average at least, a system that responds both directly to natural selection and to adaptive decision making forces will be able to adapt to varying environments more quickly than can organisms that adapt by genes and nontransmitted learning. ${ }^{22}$

In other words, human cultural evolution may be faster than biological evolution because ideas and beliefs replicate and adapt more rapidly than biological organisms. Jablonka and Lamb similarly argue that "the symbolic inheritance system" explains the unique qualities of human

\footnotetext{
${ }^{20}$ They note that Darwin himself hypothesized the importance of acquired characteristics in generating variation, in part because he did not have an adequate theory of inheritance Jablonka and Lamb, Evolution in Four Dimensions: 12-15

${ }^{21}$ Ibid., 15 .

${ }^{22}$ PJ Richerson and R Boyd, "Institutional Evolution in the Holocene: The Rise of Complex Societies" (2001):: 4
} 
evolution. ${ }^{23}$ Moreover, the significance of both genetic and symbolic inheritance means that both systems may come into conflict over time. Indeed, this layering of different instincts and their potential conflict may be an important source of continued agent variation.

The argument that human institutional design is intentional does not imply that institutional evolution is "purposive" in a teleological sense. Humans can and do intentionally change institutions with their goals, values, and objectives in mind. Humans do not, however, have the capacity to fully predict the consequences of any particular institutional change. In fact, it remains the case that at the macro level, a series of complex institutional interactions and the environment choose which variation-from institutional rules to biological mutations-will ultimately offer the group or population competitive advantages. The histories of both biological and institutional evolution are littered with examples of innovations that did not work out.

Contrary to popular misconceptions on the progressiveness of evolutionary change, the complexities of political institutions and the necessity for institutional orders to complement each other to function mean that humans cannot design perfect political institutions. Institutions are complex systems with numerous interdependent subsystems, most of which have evolved myopically at specific times to serve different functions. Political systems rarely evolve as a whole. Social, economic, and political systems, like phenotypes that describe an organism's characteristics, reflect historical legacies and past political compromises that were made to develop these systems. Current institutions are imperfect copies of earlier decisions and compromises. These compromises help to ensure imperfections in the replication of institutions

\footnotetext{
${ }^{23}$ Jablonka and Lamb, Evolution in Four Dimensions : Genetic, Epigenetic, Behavioral, and Symbolic Variation in the History of Life. See also Jared M. Diamond, The Third Chimpanzee: The Evolution and Future of the Human Animal, 1st ed. (New York, NY: HarperCollins, 1992).
} 
and thereby generate friction between subsystems, which is often a primary driver of further change.

In sum, an evolutionary approach to institutional change places human cognition, intentionality, and agency at the center of the analysis. Humans have displayed an advanced capacity to generate new rules (variation); they strategically choose between different institutional schemas (selection); and they often imperfectly implement, copy, or repeat successful behaviors (replication). In the following section we attempt to specifically show how modern institutionalist approaches have moved towards evolutionary theory.

\section{Evolutionary Foundations in the New Institutionalisms}

Institutionalists are searching for a better understanding of the mechanisms of political change. The analytic problem is that most political science models are static. Rational-choice institutionalism perceives any given institutional setting as eventually reaching an equilibrium in which "no one has the incentive to change his or her choice." ${ }^{24}$ Consequently the only source of change is exogenous. As Levi argues, "it is obvious that choices change regularly and constantly. . To understand these changes requires a set of hypotheses concerning what exogenous shocks or alterations to the independent variables will have what effects on the actions of the individuals under study." 25 According to Hall and Taylor, the foundational

\footnotetext{
${ }^{24}$ Levi, "A Model, a Method and a Map: Rational Choice in Comparative and Historical Analysis.": 27

${ }^{25}$ Ibid.
} 
assumptions and logic of rational choice means "endogenous institutional change appears. . .to be a contradiction." 26

In contrast, historical institutionalists emphasize long-term trends and use concepts such as "feedback" and "punctuated equilibrium" that allow them to explore some mechanisms of political change. ${ }^{27}$ However, they, too, have adopted a relatively reductionist perspective on institutions and view institutions as consistent and stable constraints on behavior. As James Mahoney and Kathleen Thelen observe in Explaining Institutional Change: "While institutional analysis has earned a prominent place in contemporary social science, the vast literature that has accumulated provides us with precious little guidance in making sense of processes of institutional change." 28 In other words, while it is true that institutions are often "sticky,"

\footnotetext{
${ }^{26}$ Peter Hall and Rosemary Taylor, "Political Science and the Three New Institutionalisms," Political Studies 44, (1996).: 953

${ }^{27}$ Foundational examples include Paul Pierson, "Increasing Returns, Path Dependence, and the Study of Politics," American Political Science Review 94, (2000); ___ Politics in Time: History, Institutions, and Social Analysis (Princeton: Princeton University Press, 2004); Sven Steinmo, Kathleen Ann Thelen, and Frank Longstreth, Structuring Politics : Historical Institutionalism in Comparative Analysis, Cambridge Studies in Comparative Politics (Cambridge [England] ; New York: Cambridge University Press, 1992); Wolfgang Streeck and Kathleen A. Thelen, Beyond Continuity : Institutional Change in Advanced Political Economies (Oxford ; New York: Oxford University Press, 2005); Kathleen A. Thelen, How Institutions Evolve : The Political Economy of Skills in Germany, Britain, the United States, and Japan, Cambridge Studies in Comparative Politics (Cambridge ; New York: Cambridge University Press, 2004)..

${ }^{28}$ Mahoney and Thelen, "Explaining Institutional Change: Ambiguity, Agency, and Power.": 2
} 
viewing them as rigid and stable constraints reduces a scholars's ability to explain endogenous change, relegating explanations of change to the product of "punctuated" exogenous shocks. ${ }^{29}$

New institutionalists, finding "exogenous" models of change insufficient, have explored mechanisms of gradual institutional change. This literature explicitly and implicitly borrows analytic tools from, and shares the basic ontological positions of, evolutionary theories. ${ }^{30}$ The

29 See, for example, Stephen Krasner, "Approaches to the State: Alternative Conceptions and Historical Dynanmics," Comparative Politics, (1984); Steinmo, Thelen, and Longstreth, Structuring Politics : Historical Institutionalism in Comparative Analysis; Frank R. Baumgartner and Bryan D. Jones, "Punctuations, Ideas, and Public Policy," in Policy Dynamics, ed. Frank R. Baumgartner and Bryan D. Jones (Chicago: University of Chicago Press, 2002). This position mirrors the minority view in evolutionary biology articulated by Stephen J. Gould, Wonderful Life: The Burgess Shale and the Nature of History (New York: Norton, 1989)..

${ }^{30}$ Mark Blyth, "Great Punctuations: Prediction, Randomness, and the Evolution of Comparative Political Science," American Political Science Review 100, (2006); John L. Campbell, Institutional Change and Globalization (Princeton, N.J.: Princeton University Press, 2004); Avner Greif and David Laitin, "A Theory of Endogenous Institutional Change," American Political Science Review 98, (2004); Margaret Levi, Consent, Dissent, and Patriotism, Political Economy of Institutions and Decisions (Cambridge ; New York: Cambridge University Press, 1997); Lieberman, "Ideas, Institutions, and Political Order: Explaining Political Change."; Mahoney and Thelen, "Explaining Institutional Change: Ambiguity, Agency, and Power."; Douglass C. North, Institutions, Institutional Change, and Economic Performance, The Political Economy of Institutions and Decisions (Cambridge ; New York: Cambridge University Press, 1990); Johan P. Olsen, "Change and Continuity: An Institutional Approach to Institutions of Democratic Government," European Political Science Review 1, (2009); Streeck and Thelen, Beyond Continuity : Institutional Change in Advanced Political Economies; Thelen, How Institutions Evolve : The Political Economy of Skills in Germany, Britain, the United States, and Japan; Kellee S. Tsai, "Adaptive Informal Institutions and Endogenous Institutional Change in China," World Politics 59, (2006); Andreas Wimmer and Reinhart Kössler, Understanding Change : Models, Methodologies, and Metaphors (Houndmills, Basingstoke, Hampshire, New York: Palgrave Macmillan, 2006). 
development of theories of endogenous change that complement those of punctuated exogenous change resembles the progression that has taken place in evolutionary biology, where it is now widely accepted that both gradual endogenous change (or, adaptive change) and systemic punctuation are important parts of the evolutionary account. ${ }^{31}$

Evolutionary theory and the new institutionalist literature on endogenous institutional change overlap in two ways. First, the new institutionalists have developed a less reductionist perspective on institutions and view them as "complexes" of rules rather than unified, seamless and consistent constraints. Secondly, the institutionalists, instead of focusing exclusively on either structure or agency, contend that interactions between the two drive change.

The new institutionalists implicitly moved in the direction of evolutionary theory when they gradually revised their original conception of institutions as independent, self-reinforcing and essentially stable constraints on behavior. They, instead, view institutions as sets of rules embedded within the broader institutional milieu of a polity. As Streeck and Thelen point out, "a general problem in contemporary institutional analysis" is that it "always emphasized structural constraints and continuity." Viewing institutions as "frozen residues, or 'crystallizations', of previous political conflict" had proved theoretically inadequate and did not match empirical reality. ${ }^{32}$ To better explain change, new institutionalists have embraced complexity. For example Grief and Laitin argue, "Within any organization, or around any set of rules, there are subsets of coordinated elements that are themselves institutions. Institutions can be identified

\footnotetext{
${ }^{31}$ The imminent evolutionary theorist, Stephen J. Gould, noted for his emphasis on punctuated change, seems to have moved in this direction during the last years of his life. Stephen Jay Gould, I Have Landed : The End of a Beginning in Natural History, 1st ed. (New York: Harmony Books, 2002); ——, The Structure of Evolutionary Theory (Cambridge, Mass.: Belknap Press of Harvard University Press, 2002). See also Mayr, What Evolution Is.

${ }^{32}$ Streeck and Thelen, "Introduction: Institutional Change in Advanced Political Economies.": 6
} 
therefore at different levels of aggregation." ${ }^{33}$ Similarly, Streeck and Thelen define institutions as a "social regime" comprising a set of rules that clarify desired behavior and define what is unacceptable. ${ }^{34}$ The idea of institutions as "regimes" evokes the insight that institutions are multi-layered, that they sometimes overlap, that they can be ambiguous, and that they contain contradictory logics. ${ }^{35}$ Ugo Pagano has highlighted the "complimentary" of institutions - that is, numerous institutional structures must often work jointly to perform a particular governance functions. ${ }^{36}$ In conceptualizing institutions as complexes of rules that are not always consistent yet must work together, these scholars have not only established foundations for explaining change, they have also adopted the complex ontology of generalized Darwinism.

Institutionalist scholars, in addition, have increasingly moved towards evolutionary thinking because of their increasing attention to the "interaction" between institutional structures and agents. For example, North argues that institutional change is driven by the interactions between organizations and the choices that institutions offer. ${ }^{37}$ Henry Farrell likewise focuses on interaction when he looks at the conditions under which agents strategically deviate from existing institutional rules and rationales in order to promote institutional change. ${ }^{38}$ In general, rational-choice scholars have developed a more nuanced bottom-up view of agent preferences

\footnotetext{
${ }^{33}$ Greif and Laitin, "A Theory of Endogenous Institutional Change.": 640

${ }^{34}$ Streeck and Thelen, "Introduction: Institutional Change in Advanced Political Economies.": 12

${ }^{35}$ Lieberman, "Ideas, Institutions, and Political Order: Explaining Political Change."; Streeck and Thelen, Beyond Continuity : Institutional Change in Advanced Political Economies.

${ }^{36}$ Pagano, "Legal Positions and Institutional Complementarities."

${ }^{37}$ North, Institutions, Institutional Change, and Economic Performance.

${ }^{38}$ Henry Farrell, The Political Economy of Trust : Institutions, Interests and Inter-Firm Cooperation in Italy and Germany, Cambridge Studies in Comparative Politics (Cambridge ; New York: Cambridge University Press, 2009).
} 
and the complexities of decision making, in part because they are more attuned to the ways that agents interact with and respond to institutional and environmental stimuli. ${ }^{39}$ A similar shift towards analyzing interactive processes is underway among more historically oriented institutionalists. Many of their concepts, such as "positive and negative feedback,"40 "friction,"41 "layering and conversion,"42 and "informal adaptive institutions"43 denote mechanisms of change and have become widely used. Each concept highlights the interactions among sets of rules, as well interactions between rule-makers and rule-takers. In their reflections on gradual change, Streeck and Thelen, for example, argue that institutions are determined by the continuous interaction between rule-makers and rule-takers, during which new interpretations of the rule will be discovered, invented, rejected, and maybe adopted. ${ }^{44}$

Finally, interpretivist scholars increasingly view political systems as complexes of interdependent rules that must complement each other to function well and that often imperfectly replicate. Conceptualizing institutions at different levels of analysis mirrors fashions in evolutionary theory, such as "multi-level selection theory," which argues that selection pressures

\footnotetext{
${ }^{39}$ Ira Katznelson and Barry R. Weingast, Preferences and Situations : Points of Intersection between Historical and Rational Choice Institutionalism (New York: Russell Sage Foundation, 2005); Rose McDermott, James H. Fowler, and Oleg Smirnov, "On the Evolutionary Origin of Prospect Theory Preferences," Journal of Politics 70, (2008).

${ }^{40}$ Pierson, "Increasing Returns, Path Dependence, and the Study of Politics."

${ }^{41}$ Lieberman, "Ideas, Institutions, and Political Order: Explaining Political Change."

${ }^{42}$ Thelen, How Institutions Evolve : The Political Economy of Skills in Germany, Britain, the United States, and Japan.

${ }^{43}$ Tsai, "Adaptive Informal Institutions and Endogenous Institutional Change in China."

${ }^{44}$ Streeck and Thelen, "Introduction: Institutional Change in Advanced Political Economies.": 16.
} 
can take place at multiple levels of analysis. ${ }^{45}$ This helps to explain the origins of institutionswhich are often designed to solve collective-action problems - as well as the emergence of both cooperative and competitive behaviors. ${ }^{46}$ The constant interactions between individuals, groups, and their environment are also the central mechanisms of change in evolutionary theory. This ontological position draws institutionalists much closer to the "interactionist paradigm" of evolutionary theory.

\section{Towards an Evolutionary Theory of Institutional Change}

While it is beyond the scope of this article to address fully all the complex issues involved in a full-blown, comprehensive theory of institutional change, generalized evolutionary theory does provide both an explicit framework for understanding the mechanisms of change, and a broad conceptual framework for integrating a wide array of nuanced theories related to these processes. To date most innovations in the literature on endogenous institutional change have been ad hoc and based on either particular questions or distinct analytical problems. They have lacked an overarching theoretical framework that ties the innovations together and helps shape thinking in the field. An evolutionary framework does just that. It helps integrate and explain many of these analyses, and thus illuminates an ongoing research agenda for an interrelated body of theories of gradual institutional change. While not presuming to present a complete theory of institutional change, the second part of this article highlights existing social-

\footnotetext{
${ }^{45}$ Alford and Hibbing, "The Origins of Politics: An Evolutionary Theory of Political Behavior."; Elliott Sober and David Sloan Wilson, Unto Others : The Evolution and Psychology of Unselfish Behavior (Cambridge, Mass.: Harvard University Press, 1998).

${ }^{46}$ John Orbell et al., "Machiavellianî Intelligence as a Basis for the Evolution of Cooperative Dispositions," American Political Science Review 98, (2004).
} 
science research in three areas and thereby contributes to the building of an integrated body of research.

\section{Cognition, Preferences and Variation}

The origins of preferences and sources of agent variation have been the focus of a growing literature on the evolutionary foundations of political preferences and human decision-

making. ${ }^{47}$ Such work has been supported by the cognitive revolution in psychology and the social sciences as well as work in cognitive neuroscience that "has also begun to incorporate emotion and motivation into cognitively oriented theories of choice." 48

An evolutionary framework helps address one of the more vexing problems confronting instituitionalists today: the relationship between ideas, preferences, and institutions. Katznelson and Weingast point out that, "[p]references are foundational for any theory that relies on agency," but, "[w]e know too little about preferences, where they come from, or how they are

\footnotetext{
${ }^{47}$ Alford and Hibbing, "The Origins of Politics: An Evolutionary Theory of Political Behavior."; John R. Alford, Carolyn L. Funk, and John R. Hibbing, "Are Political Orientations Genetically Transmitted?," American Political Science Review 99, (2005); Christopher T. Dawes and James H. Fowler, "Partisanship, Voting, and the Dopamine D2 Receptor Gene," Journal of Politics 71, (2009); J. H. Fowler, L. A. Baker, and C. T. Dawes, "Genetic Variation in Political Participation," American Political Science Review 102, (2008); James H. Fowler and Christopher T. Dawes, "Two Genes Predict Voter Turnout," Journal of Politics 70, (2008); Peter K. Hatemi et al., "Is There A "Party" In Your Genes?," Political Research Quarterly 62, (2009); R McDermott, "The Feeling of Rationality: The Meaning of Neuroscientific Advances for Political Science," Perspectives on Politics 2, (2004); McDermott, Fowler, and Smirnov, "On the Evolutionary Origin of Prospect Theory Preferences.".

${ }^{48}$ McDermott, Fowler, and Smirnov, "On the Evolutionary Origin of Prospect Theory Preferences.": 335
} 
generated. ${ }^{49}$ Traditionally, rational-choice institutionalist scholars assume stable preferences. ${ }^{50}$ Conversely, historicists tend to see preferences as far less stable and instead argue that institutions structure preferences. ${ }^{51}$ Katznelson and Weingast, for example, contend that they can "derive" preferences based on the "compelling logic of institutions embedded in particular historical situations." ${ }^{, 52}$ The problem with these two traditional approaches is that neither helps to explain change because both reduce preferences without investigating their origins and both tend to view preferences as relatively consistent across individuals. In other words, there is little explanation of agent variation or how preferences change.

${ }^{49}$ Katznelson and Weingast, Preferences and Situations : Points of Intersection between Historical and Rational Choice Institutionalism : 2

50 Jon Elster, "Rational Choice History: A Case of Excessive Ambition," American Political Science Review 94, (2000); — - "Rational Choice Theory and Comparative Politics" (paper presented at the Russell Sage Foundation Conference on Rational Choice and Historical Institutionalism, New York, April 7-8 2001); Douglass Cecil North, Transaction Costs, Institutions, and Economic Performance (San Francisco, Calif.: ICS Press, 1992); Barry R. Weingast, "Persuasion, Preference Change, and Critical Junctures: The Microfoundations of a Macroscopic Concept," in Preferences and Situations: Points of Intersection between Historical and Rational Choice Institutionalism, ed. Ira Katznelson and Barry R. Weingast (New York: Russell Sage Foundation Publications, 2007).

${ }^{51}$ Peter Hall, "The Role of Interests, Institutions and Ideas in Comparative Political Economy of the Industrialized Nations," in Comparative Politics: Rationality, Culture and Structure, ed. Mark Lichbach and Alan Zucherman (New York: Cambridge University Press, 1997); Sven Steinmo, "Political Institutions and Tax Policy in the United States, Sweden and Britain," World Politics XLI, (1989); __, "Why Is Government So Small in America?," Governance 8, (1995).

${ }^{52}$ Katznelson and Weingast, Preferences and Situations : Points of Intersection between Historical and Rational Choice Institutionalism : 2 
One method for addressing these questions is to develop a more explicitly evolutionarycognitive approach to preferences. As Douglass North observes:

the dynamic nature of history implies that the centrality of beliefs - how humans form their beliefs and how they learn- is fundamental to a new social science. This in turn leads us to two inquiries: first, how the mind and brain work to understand their environment; second, how humans learn from one another, for example through culture. ${ }^{53}$

Kurt Weyland also propounds this approach to micro-foundations. He argues that positing preferences rooted in an evolutionary framework has

the advantage of resting on a wealth of well-corroborated empirical findings about human decision making. By contrast, rational choice, the approach that is most insistent on the need for a microfoundation, derives its models from ideal-type postulates about comprehensive rationality that lack realism and that are systematically falsified in psychological studies. ${ }^{54}$

At one extreme of micro-analysis, such researchers as Alford et al. have found a genetically heritable component to political behavior, ${ }^{55}$ a genetic component to political ideologies, and genetic predispositions toward liberalism and conservatism. ${ }^{56}$ Fowler et al. likewise argue that humans exhibit "inherent variability" in their propensity to participate in

${ }^{53}$ Douglass Cecil North, "What Is Missing from Political Economy," in The Oxford Handbook of Political Economy, ed. Barry R. Weingast and Donald A. Wittman (Oxford: Oxford University Press, 2008).: 1005

${ }^{54}$ Kurt Weyland, "Toward a New Theory of Institutional Change," World Politics 60, (2008).: 285-86; See also Orbell et al., "Machiavellianî Intelligence as a Basis for the Evolution of Cooperative Dispositions."

${ }^{55}$ Alford, Funk, and Hibbing, "Are Political Orientations Genetically Transmitted?."; Fowler, Baker, and Dawes, "Genetic Variation in Political Participation."; Fowler and Dawes, "Two Genes Predict Voter Turnout."

${ }^{56}$ Alford, Funk, and Hibbing, "Are Political Orientations Genetically Transmitted?." 
politics, and Fowler and Dawes have identified two genes linked to voter participation. ${ }^{57}$ Fowler and his co-authors also claim to have presented "first results ever to link specific genes to political behavior." ${ }^{, 58}$ Alford and Hibbing point out that while scholars often talk about different types of individuals, in reality individuals often fall along a spectrum. ${ }^{59}$ Within any population, individuals vary greatly at the genetic level, which determines their predisposition for internalizing various schemas.

While an evolutionary perspective can help us understand the origins of human preferences and the sources of variation, this perspective is not genetic determinism. Personal experience and environmental factors still play large roles in determining whether and how genetic predispositions are articulated. ${ }^{60}$ Working along these lines, McDermott et al. argue that evolutionary theory illuminates the cognitive "biases" that scholars consistently discover in one of the most consequential social-science frameworks: prospect theory. Ever since Kahneman and Tversky chronicled a number of cognitive "biases" causing human decision-making to deviate from a the purely "rational" calculations, ${ }^{61}$ prospect theory has become "one of the most influential behavior theories of choice in the wider social sciences." ${ }^{\prime 62}$ Scholars working in this

${ }^{57}$ Fowler, Baker, and Dawes, "Genetic Variation in Political Participation."; Fowler and Dawes, "Two Genes Predict Voter Turnout."

${ }^{58}$ Fowler and Dawes, "Two Genes Predict Voter Turnout.": 579

${ }^{59}$ Alford and Hibbing, "The Origins of Politics: An Evolutionary Theory of Political Behavior."

${ }^{60}$ Alford, Funk, and Hibbing, "Are Political Orientations Genetically Transmitted?."; Fowler and Dawes, "Two Genes Predict Voter Turnout."

${ }^{61}$ Daniel Kahneman and Amos Tversky, "Prospect Theory: An Analysis of Decision under Risk," Econometrica: Journal of the Econometric Society 47, (1979); A. Tversky and D. Kahneman, "The Framing of Decisions and the Psychology of Choice," Science 211, (1981).

${ }^{62}$ McDermott, Fowler, and Smirnov, "On the Evolutionary Origin of Prospect Theory Preferences.": 335 
tradition consistently have found that individuals shift their risk propensity based on whether they face losses or gains. Individuals tend to be more risk-averse when facing gains and riskacceptant when faced with losses. Research on change in cognitive biases also includes a robust literature on "framing effects," which has shown that individuals choose differently depending on the way that information is presented to them and the values that it emphasizes. ${ }^{63}$ McDermott et al. explain this variability in preferences as the product of evolutionary adaptations that helped early hunter-gathers better survive. These researchers argue that "leaders who demonstrate flexibility and the ability to switch strategies based on particular environmental contingencies may [succeed] best of all." ${ }^{\prime 64}$

This research implicitly rests on a notion of "ecological rationality," which understands rationality as deeply embedded within the environmental and institutional context that individual agents face. The concept of "ecological rationality" can help researchers better understand how and why preferences vary. It recognizes both the interactive nature of evolutionary change and the fact that agent preferences are dialectically shaped by the broader selection pressures that an individual faces.

This research, furthermore, has found that human preferences are not neatly structured and consistent. They are, in fact, complex, multi-layered, overlapping, and sometimes competing. For example, individuals face dilemmas, change their minds, and behave

${ }^{63}$ D. Chong and J. N. Druckman, "A Theory of Framing and Opinion Formation in Competitive Elite Environments," Journal of Communication 57, (2007); —_ _ "Framing Theory," Annual Review of Political Science 10, (2007); Dietram A. Scheufele and David Tewksbury, "Framing, Agenda Setting, and Priming: The Evolution of Three Media Effects Models," Journal of Communication 57, (2007).

${ }^{64}$ McDermott, Fowler, and Smirnov, "On the Evolutionary Origin of Prospect Theory Preferences.": 343 
inconsistently because they are concerned about both individual and group-oriented utility. ${ }^{65}$ Group identities are often salient influences on an individual's decision-making, yet they may conflict with an individual's self-interest. According to Richerson and Boyd, "These ancient [genetic] social instincts conflict with the tribal. We are simultaneously committed to tribes, family, and self, even though conflicting demands very often cause us great anguish."66

To summarize, a cognitive view of preferences makes it difficult to reduce them to a few dimensions, and provides a clear understanding of how preferences and decision-making change in response to new environmental stimuli. Recent research rooted in an evolutionary approach to cognition, allows researchers to posit three sources of agent variation. First, genetic variation generates a distribution of preferences in any population. Secondly, because of preference complexity, decision-making can be malleable and inconsistent, and can exhibit biases. Preferences often overlap and clash. According to Bueno de Mesquita and McDermott, individuals, when asked to compare across different reference points and frames, often change their preference ordering or vary in their preference weighting. ${ }^{67}$ This helps us explain why human preferences are not always consistent, coherent, and cogent, and why public opinion is prone to significant shifts depending on available information. Thirdly, the iterated interaction of agent preferences with institutional and environmental factors ultimately determines behavior. To the extent that cultural, institutional, and environmental backgrounds vary, then preferences

${ }^{65}$ Howard Margolis, Selfishness, Altruism, and Rationality : A Theory of Social Choice (Chicago: University of Chicago Press, 1984).

${ }^{66}$ Peter J. Richerson and Robert Boyd, "Institutional Evolution in the Holocene: The Rise of Complex Societies," in The Origin of Human Social Institutions, ed. W.G. Runciman (Oxford: Oxford University Press, 2001).: 201

${ }^{67}$ Bruce Bueno de Mesquita and Rose McDermott, "Crossing No Man's Land: Cooperation from the Trenches," Political Psychology 25, (2004).: 272 
also vary. Real human beings - not the homo-economicus hypothesized much of the literaturehave multi-layered, sometimes conflicting, preferences drawn from both their personal histories and their genetic past. In this regard, Bueno de Mesquita and McDermott argue that rationalist and psychological models of decision making complement each other and contribute to more robust theorizing on the origin of preferences. ${ }^{68}$ In addition, imperfect replication of the genetic and institutional rules that drive human behavior means that a certain degree of agent variation will continually and always exist.

This leads to a two important analytical points. First, one should expect significant agent variation even within the same local institutional system. Second, simply knowing that agents vary in their preferences, or even what an agents basic preference structure is, will likely not be sufficient to explain behavior. To understand which cognitive schemas and ideas are activated and proliferate requires a detailed analysis of the interaction over time of agent preferences with institutional and environmental mechanisms of selection. The following section theorizes about these selection mechanisms.

\section{Selection}

Humans, more than any other species, have evolved complicated mechanisms and institutions to shape behavior and promote cooperative strategies that benefit their groups. To understand these developments, evolutionary theorists have employed the concept of "group selection" and the theory of "multilevel selection" (or, MLS) ${ }^{69}$ Thus, evolutionary history is not

\footnotetext{
${ }^{68}$ Ibid.: 272

${ }^{69}$ Alford and Hibbing, "The Origins of Politics: An Evolutionary Theory of Political Behavior."; Darwin, The Descent of Man; Sober and Wilson, Unto Others : The Evolution and Psychology of Unselfish Behavior.
} 
just about how single individuals adapt to fitness pressures, but also about how groups sometimes compete with one another in terms of relative fitness.

MLS answers important puzzles regarding socially cooperative behaviors, by arguing that selfless actions may benefit the group even if they are not individually beneficial. For example, in The Descent of Man, Darwin invokes the concept of group selection to explain the evolution of morality. He argues, "It must not be forgotten that although a high standard of morality gives but a slight or no advantage to each individual man and his children. . advancement in the standard of morality will certainly give an immense advantage to one tribe over another."70 Alford and Hibbing point out that MLS explains how altruism and morality can be an advantageous adaptation for societies in the midst of inter-group competition. ${ }^{71}$ Orbell et al. find that "Machiavellian intelligence" contributes to the development of socially cooperative behaviors, because it involves the cognitive capacity to negotiate "competitive and highly complex social environment of the group."72 By extension, many social institutions can be seen as rules that promote cooperative behavior in the group's interest and solve collective-action problems.

While the notion of multilevel-selection pressures helps to explain the creation of institutions and their contributions to cooperation, it also requires that researchers be explicit about the mechanisms of selection at each level of analysis: individual, organizational (that is, group or institutional), systemic, and global. Traditionally, selection revolved around "fitness," which is some measure of success. The key question becomes: success at what? Eric

\footnotetext{
${ }^{70}$ Quoted in Sober and Wilson, Unto Others : The Evolution and Psychology of Unselfish Behavior.: 8; Darwin, The Descent of Man.

${ }^{71}$ Alford and Hibbing, "The Origins of Politics: An Evolutionary Theory of Political Behavior."

72 Orbell et al., "Machiavellianî Intelligence as a Basis for the Evolution of Cooperative Dispositions.": 2
} 
Beinhocker argues fitness can be seen as a computational-search algorithm that continually looks for the best economic design. This implies constant comparisons within the marketplace of ideas for policy designs, with innovative ideas constantly competing with one another. ${ }^{73}$

An evolutionary approach offers an iterated multi-level theory of institutional selection. At the more micro-level of analysis, governments make decisions about how to create, reform, and update institutional rules. Institutionalism has a rich history of detailing how different political structures choose policy. The actors involved in selecting institutional structures and reforms have become known generally as the "selectorate"-or, the group of people that influence formal decision-making. ${ }^{74}$ Selectorates vary in size and in their openness to societal input. Political institutions, via the selectorate, define the Lamarckian aspects of institutional evolution. That is, governments make targeted decisions for institutional reform, and seek artificially to shape social outcomes by generating new mechanisms of social selection in addition to natural selection. ${ }^{75}$

While institutional reforms are often made logically with some performance expectations, their "fitness" cannot be predicted. Fitness can be discovered only after the reforms have been enacted, and the newly reformed institutions have had an opportunity to interact with their institutional subsystems. This stage of selection - known in the aggregate as environmental selection-involves an extremely complex set of interactions among institutional rules, existing subsystems, and agents. This complex interaction ultimately determines how institutions perform, generates feedback, and informs additional selectorate decisions. Even though the

\footnotetext{
${ }^{73}$ Beinhocker, The Origin of Wealth : Evolution, Complexity, and the Radical Remaking of Economics.

${ }^{74}$ Bruce Bueno de Mesquita, The Logic of Political Survival (Cambridge, Mass.: MIT Press, 2003).

${ }^{75}$ Boyd and Richerson, Culture and the Evolutionary Process; Richerson and Boyd, Not by Genes Alone : How Culture Transformed Human Evolution.
} 
reformers' expectations for institutional reforms are often informed and logically deduced, the expectations remain only hypotheses about how policy changes will work once implemented. To completely gauge the fitness of an institutional reform, it must be tried and tested.

The environmental framework for theorizing selection has several important implications for understanding institutional change. First, just as evolutionary adaptations in biological systems often require complementary changes among subsystems, institutions do not evolve independently. Though one may observe long periods of relatively slow change-what is sometimes called stasis - true equilibrium is impossible in an evolutionary system. What appear to be slow periods of stasis, in fact, mask gradual shifts that are a constant of evolutionary systems. When multiple changes amongst subsystems coincide, the long-term systemic consequences can be very important. ${ }^{76}$ This explains why a tipping point, followed by rapid "punctuated" change, often follows long periods of relative stasis. ${ }^{77}$ To understand how a particular institutional reform (in other words, adaptation) performs, social scientists must consider how these changes interact with other existing institutions. This implies greater attention to the co-evolution of institutions. ${ }^{78}$

\section{Replication and the Nature of Institutional Change}

Institutions can be understood as rules that are passed from one generation to the next, that are imperfectly replicated over time, and that must be understood as part of the broader

\footnotetext{
${ }^{76}$ N. Gontier, "Evolutionary Epistemology and the Origin and Evolution of Language: Taking Symbiogenesis Seriously," Evolutionary Epistemology, Language and Culture, (2006).

${ }^{77}$ Weyland, "Toward a New Theory of Institutional Change."

${ }^{78}$ S Bowles, JK Choi, and A Hopfensitz, "The Co-Evolution of Individual Behaviors and Social Institutions," Journal of Theoretical Biology 223, (2003).
} 
environment in which they operate. However, the means of replication in political and biological systems differ in important ways. To understand replication, one must investigate the means by which information is structured and transferred to latter generations (in other words, the genes of politics).

At the most basic level, sociologically oriented scholars have defined institutional replicators abstractly as "schemas" or "routines,"79 which are the cognitive rules that tell individuals that given situation $\mathrm{X}$, one should do $\mathrm{Y}$. Institutions are thus defined as intersubjectively understood schemas about formal and informal rules of behavior. Johan Stein, for example, argues that institutions are a mental construction of the world created through a process of "reduction and elaboration." 80 Because individuals' attention and cognitive capacity are limited, humans rely heavily on such "schemas." They perform a similar role as "ideas" 81 or "policy paradigms" 82 do in that they are a coherent set of interrelated propositions that inform one's view of how the world works, one's goals, and the means of achieving them.

From a cognitive perspective, institutional efficacy relies on the internalization of schemas that tell individuals how they should behave. Unlike some scholars, we distinguish "schemas" from "ideas," which are conscious, creative solutions to collective-action problems. Schemas, in contract, are "unconscious" cognitive rules that individuals regularly use. This

\footnotetext{
${ }^{79}$ Campbell, Institutional Change and Globalization; Richard R. Nelson and Sidney G. Winter, An Evolutionary Theory of Economic Change (Cambridge, Mass.: Belknap Press of Harvard University Press, 1982).

${ }^{80}$ J Stein, "How Institutions Learn: A Socio-Cognitive Perspective," Journal of Economic Issues 31, (1997).

${ }^{81}$ Mark Blyth, Great Transformations: Economic Ideas and Institutional Change in the Twentieth Century (New York: Cambridge University Press, 2002).

${ }^{82}$ Peter Hall, "Policy Paradigms, Social Learning, and the State: The Case of Economic Policymaking in Britain," Comparative Politics 25, (1993).
} 
distinction makes it relatively easy to understand why institutional rules never perfectly replicate behavior. Replication relies on the uncritical acceptance of and adherence to rules. As long as individuals vary in their conceptions of the content and implementation of rules, then imperfections in replication (and hence variation) will continue within a system. Moreover, while institutional schemas are designed to structure or "select" certain behaviors, they do not always determine behavior and often allow for multiple solutions to a given problem. ${ }^{83}$ Like selection more broadly, institutional rules allow multiple specific behaviors to exist simultaneously at the micro-level.

A second important difference between institutional and biological replication is the ease by which institutional schemas can change. Given human's advanced capacity for communication and learning, there are limits to the biological analogy of vertical evolution through inter-generational and "unconscious" genetic change. ${ }^{84}$ Despite the significance of institutional schemas, humans have a unique ability to generate new ideas and institutional innovations (in other words, mutations) that other humans can intentionally copy and replicate. The notion of inter-subjectively understood schemas makes it easy to understand the ample opportunities for alternative ideas and variations to emerge, as well as agents' flexibility in reinterpreting rules. Indeed, a defining aspect of institutional evolution is that it is driven by

\footnotetext{
${ }^{83}$ Mark Blyth, "Structures Do Not Come with an Instruction Sheet: Interests, Ideas and Progress in Political Science," Perspectives on Politics 1, (2003).

${ }^{84}$ For example, Nathalie Gontier, in "Evolutionary Epistemology and the Origin and Evolution of Language: Taking Symbiogenesis Seriously," argues that theories of genetic change based on biologically based theories of natural selection are inadequate for the study of human language and culture. Humans' capacity to actively borrow and re-combine traits gives these institutions peculiar properties that are better explained by "horizontal" evolution.
} 
conscious strategic action. Genes cannot consciously copy innovations and mutations, but humans can and often do. As Jablonka and Lamb argue, contrary to current dogma, the variation on which natural selection acts is not always random in origin or blind in function. Variation is often targeted, in the sense that it preferentially affects functions or activities that can make organisms better adapted to the environment in which they live [emphasis in original]. ${ }^{85}$

The evolutionary framework clarifies why the structure of ideas and their proliferation should be foci in studies of institutional evolution. It helps to integrate and synthesize studies of the role of cognition, decision-making, and ideas. While ideational variables have not found a theoretical home traditional political-science theory, they can be readily understood in evolutionary terms, in which they play a role analogous to mutations in both replicating existing institutions while simultaneously generating new variation and hybridization. Indeed, some of the most interesting work in the new institutionalist tradition is found amongst those who try to understand the ways in which ideas, values, and beliefs affect political history, and who use these insights to understand institutional change. ${ }^{86}$ These scholars view institutional change as the product of changes in policy ideas held by key actors. Change occurs when powerful agents adopt new policies as a result of changes in perspective on how the world works - changes

\footnotetext{
85 Jablonka and Lamb, Evolution in Four Dimensions : Genetic, Epigenetic, Behavioral, and Symbolic Variation in the History of Life.: 319

${ }^{86}$ Sheri Berman, "Ideational Analysis in Political Science," (Princeton NJ: Princeton University, 1998); ——, "Ideas, Norms and Culture in Political Analysis," Comparative Politics, (2001); Campbell, Institutional Change and Globalization.
} 
spawned by either theory or new information. ${ }^{87}$ Seen in this way, ideas are not "irrational," but creative adaptations. $^{88}$

Many institutionalists have conceptualized the scope conditions and mechanisms of ideational change in political systems. Mark Blyth suggests that the adoption of new ideas is most likely during periods of "Knightian uncertainty" when environmental changes encourage the questioning of conventional schemas and when new ideas have an opportunity to fit the new environmental context. ${ }^{89}$ While rapid ideational change often occurs during periods of dramatic uncertainty, ideas also can proliferate gradually due to "friction" in institutional orders. ${ }^{90}$ Kellee Tsai, for instance, has highlighted the proliferation of "informal adaptive institutions" as a creative response to the constraints of formal economic institutions in China ${ }^{91}$; and Nadav Shelef, in a study of the evolution of nationalism in Israel, has differentiated between the selectorate-driven "elite imposition" and bottom-up "rational adaptation" that often diverge, clash, and generate friction. ${ }^{92}$

However strategic, targeted political selection by those with power is only one way that schemas and behaviors are replicated. Perceptions of the relative fitness of a particular policy

\footnotetext{
${ }^{87}$ For a precise application of this approach with respect to free-trade institutions, see James A. Morrison, "Before Hegemony: Adam Smith, American Independence, and the Origins of the First Era of Globalization," International Organization, (fothcoming 2012).

${ }^{88}$ There has been an unfortunate and unnecessary tendency to juxtapose "ideational" analysis against "rational" choice.

${ }^{89}$ Blyth, Great Transformations: Economic Ideas and Institutional Change in the Twentieth Century.

${ }^{90}$ Lieberman, "Ideas, Institutions, and Political Order: Explaining Political Change."

${ }^{91}$ Tsai, "Adaptive Informal Institutions and Endogenous Institutional Change in China.": 116

${ }^{92}$ Shelef, Evolving Nationalism : Homeland, Identity, and Religion in Israel, 1925-2005.
} 
idea are also driven by how well an institutional rule performs, particularly in conjunction with existing complimentary institutions and subsystems (as was outlined in the previous section). While we should expect schemas perceived to do well to proliferate amongst political decisionmaking bodies, there are often natural limits to their implementation within the broader political ecology. Schema replication is not just the product of conscious human selection, but is also determined by environmental selection-how well an institutional rule performs in conjunction with complimentary institutions and subsystems.

In biological systems, both the complexity of gene interaction at the micro-level, and the interaction between genetic rules and the broader environmental context, contribute to the imperfect replication of institutional rules. Even in biological systems, where DNA serves as a better replicator than formal institutional rules, there remains substantial variation across individual organisms. ${ }^{93}$ Not even genetic clones are perfectly alike. ${ }^{94}$

Similarly, complex interactions between institutional orders result in significant variation across similar political systems. Even when formal institutions have been explicitly copied-for example, efforts to build Westminster democracy in Africa - the political results often differ greatly. Sven Steinmo has found that even after adopting important elements of the U.S. regulatory economic model, the Japanese economy failed to rebound in the 1990s, because the new institutional rules encountered friction from traditional welfare institutions premised on the primacy of the corporation. ${ }^{95}$ The ways in which abstract formal rules are implemented varies

${ }^{93}$ GM Hodgson, "Darwinism in Economics: From Analogy to Ontology," Journal of Evolutionary Economics 12, (2002).

${ }^{94}$ Lewontin, The Triple Helix: Gene, Organism and Environment.

95 Sven Steinmo, The Evolution of Modern States : Sweden, Japan, and the United States, Cambridge Studies in Comparative Politics (Cambridge ; New York: Cambridge University Press, 2010). 
across political systems because of the rules' interaction with other institutions, formal and informal.

A key contingent determinant of institutional replication is the "complimentarity" of institutional changes. Evolution is often inefficient at an aggregate or macro level, and different subsystems may not work together in a coordinated fashion. This insight can help scholars understand why change is difficult and often sporadic. Increased complexity alone does not necessarily yield competitive advantages. As systems become more and more complex, friction between subsystems increases, as does the need for coordinating and complementing functions among constituent parts. Growing stronger arms and legs might improve speed, but unless the heart grows stronger simultaneously, a stronger body could easily undermine the long-term health and reproductive capacity of a particular species. According to Lieberman, friction between institutional orders - such as an organization's institutional mandate and its capacity to carry out that function - is often the root cause of conflict, forcing actors to search creatively for solutions or adaptations. ${ }^{96}$ This pattern of "friction leading to gradual change" is observed repeatedly in the literature on endogenous institutional change outlined above. Its study requires that researchers analyze not just a particular rule, but also (1) how that institutional rule interacts with other elements in the system and (2) constraints on the replication of that rule.

In sum, focusing research on the process of institutional replication-that is, the scope and pace by which schemas proliferate, are embedded, and change-illuminates fundamental questions about the basic mechanisms of institutional change. While genetic change in the biological world is relatively slow and occurs over multiple generations, human institutions are often built with the capacity to incorporate feedback and to make multiple adjustments within a

\footnotetext{
${ }^{96}$ Lieberman, "Ideas, Institutions, and Political Order: Explaining Political Change."
} 
single agent's lifetime. Humans' advanced capacity for information transfer and their ability to learn from mistakes and to incorporate rapidly new information about institutional fitness mean that evolutionary institutional change is likely to proceed much faster than what occurs through unconscious genetic replication. As one anonymous reviewer noted, the body politic may discard policy innovations much more easily than does a biological organism that screens genetic mutations. Nevertheless, policy ideas that "fail" to be adopted at one point are never permanently eliminated. Instead, they ensure continued variation and, by remaining possible courses of action, expand the scope for future rounds of selection.

This iterated variation-selection-replication process highlights how power holders within regimes select and direct policy ideas. But the relative success of institutional rules is known only after implementation, when the rules' interactions and functions in the political system have been repeatedly evaluated. The rapidity with which this process is iterated can raise testable hypotheses about the importance of the rate of change, or the "evolvability" of a system. Such research would focus on the opportunities for new ideas to emerge and proliferate, on their selection, and on mechanisms that constrain selection. For example, one might hypothesize that in polities that allow for greater diversity of ideas, new ideas emerge and variation occurs at a faster rate than they do in relatively closed polities. Democracies, moreover, may be faster to adapt responses that are broadly popular and slower to deploy rule changes that are unpopular. Conversely, autocracies may stifle economic innovation by stifling learning and ideational change. Likewise, more complex bureaucracies may be more difficult to change due to the friction generated between multiple agencies and interests.

\section{Conclusion}

This article has not offered a complete model of institutional evolution. Our intention is 
to introduce the reader to increasingly common notions of generalized Darwinism and to suggest that these concepts offer significant insights for understanding endogenous institutional change. This framework helps researchers move away from a reductionist and static ontology to one that highlights change and the importance of complexity, variation, and interaction. According to this perspective, institutional replication and change arise primarily from the proliferation and internalization of ideas and cognitive schemas. By integrating ideas into the analysis of institutional change, generalized Darwinism makes institutions both replicators of behaviour and objects of contestation.

Integrating ideas into institutional analysis also allows for a better understanding of mechanisms of institutional evolution. The internalization of ideas is affected by the ways that ideas are framed, the degree to which they are perceived as a relevant solution to current environmental challenges, and the extent to which they are undermined by negative feedback. Ideas are the product of agent variation at the micro-level, are impacted by selection pressures, and are imperfectly replicated. Even if institutions adopt certain ideas and preferences, variation will continue to characterize the system. Darwinist principles provide a solid foundation for thinking about all of these phenomena.

Viewing institutions in this way also integrates analyses of agency and structure because of the focus on the iterated interactions of agents and their environment. One could argue institutionalism in the past was overly structural, and that actors were viewed incorrectly as hostages of the institutions that they inhabit. By conceptualizing institutions as inter-subjectively understood schemas, scholars who analyse institutions can better understand the considerable space for agent variation and for the creation of new ideas and strategies that impact how institutions function and evolve. 
Political scientists generally, and new institutionalists specifically, have already adopted many elements of this framework. But they lack a comprehensive foundation for integrating these various lines of research. An evolutionary framework does not supplant current lines of research but, instead, serves to highlight them, integrate them, and outline areas that require further elaboration. ${ }^{97}$

The framework, in addition, points to areas for future research, regarding the emergence and proliferation of policy ideas, the mechanisms of selection and feedback, and the evolutionary potential of different systems. This is of course not an exhaustive list. It is simply one step in defining a more comprehensive and robust agenda for studying political change.

\footnotetext{
${ }^{97}$ In a recent Polity article, Ian Lustick has shown how much of the historical institutionalist literature can benefit from key evolutionary concepts and theories. I.S. Lustick, "Taking Evolution Seriously: Historical Institutionalism and Evolutionary Theory," Polity 43, (2011).
} 